\title{
Defect Detection in the Winding Layer of CNG Composite-Wound Cylindersvirtue of minimal mechanism is that it allows
}

\author{
Hui Lv ${ }^{1,2} \cdot$ Gongtian Shen ${ }^{3} \cdot$ Yue Yu ${ }^{3}$ Lixiong Zhu ${ }^{1,2} \cdot$ Rui Zhou $^{1,2}$ (D)
}

Received: 5 March 2021 / Revised: 23 June 2021 / Accepted: 29 August 2021 / Published online: 27 September 2021

(c) The Author(s) 2021, corrected publication 2021

\begin{abstract}
Natural gas vehicles have been widely used around the world as a mode of green transportation. The defect detection method for a vehicle cylinder, which is the energy storage component of a natural gas vehicle, is essential for ensuring safety. Current vehicle cylinder testing methods are relatively simple and cannot quickly and accurately detect internal defects in the winding layer of the cylinder. In this study, the effect of winding layer defects on the temperature behavior of cylinders during filling was studied using finite element simulation and infrared thermal imaging technology. The results show that a defect in the winding layer acts as a source of thermal resistance that hinders heat transfer. The more serious the defect is, the greater the hindrance of the heat transfer is. According to this principle, an evaluation model based on the $\mathrm{R}$ parameter was developed for the temperature changes due to defects, and a method for quantitatively correlating the maximum $R$ value with the defect depth was established, thereby providing a practical approach for the rapid detection and evaluation of defects in cylinder winding layers.
\end{abstract}

Keywords Composite-wound cylinders $\cdot$ Filling process $\cdot$ Defect detection $\cdot$ ANSYS $\cdot$ Temperature distribution

\section{Introduction}

Vehicles that use natural gas, which are called NGVs (natural gas vehicles), have the advantages of low fuel costs, low environmental pollution impacts, and good combustion stability compared with conventional vehicles [1]. NGVs are used worldwide and promoted as a mode of green transportation. By the end of 2018, the total number of NGVs in the world exceeded 26 million, making these vehicles one of the most promising clean energy vehicles [2-4]. There are three major methods for the high-density storage of natural gas: liquefied natural gas (LNG), compressed natural gas (CNG), and adsorbed natural gas (ANG). The most commonly used

Rui Zhou

zhour@tsinghua.edu.cn

1 Institute of Public Safety Research, Department of Engineering Physics, Tsinghua University, Beijing 100084, China

2 Beijing Key Laboratory of City Integrated Emergency Response Science, Tsinghua University, Beijing 100084, China

3 China Special Equipment Inspection and Research Institute, Beijing 100029, China method is CNG [5], and the core component of an NGV is the $\mathrm{CNG}$ cylinder.

The volume and weight of the cylinders are strictly limited in CNG vehicles. To increase the energy storage, it is necessary to maximize the filling pressure while minimizing the weight of the CNG cylinder, which obviously poses a considerable challenge for the safety of the cylinders [6]. The materials and structure of CNG cylinders for vehicles have continually evolved, as the requirements for reduced weight, increased energy storage, and safety have increased [7-14]. The US standard ANSI/CSA NGV2-1992 (American National Standard for Natural Gas Vehicle Containers) first classified the cylinders into four basic types according to their structure and materials. Currently, the vehicle gas cylinders in China are mainly CNG-II type hoop-wrapped cylinders with metal liners. This type of cylinder has a steel liner and is reinforced with an outer composite winding layer. Under the same pressure and volume conditions, this type of cylinder is $1 / 3$ lighter than a steel cylinder. The overall cost of the cylinder is reasonable, which is favorable for marketing. The winding layer serves two functions: absorbing external impacts and damage to protect the liner and limiting the debris generated from liner explosions to the maximum extent to protect the vehicle and the passengers 
[15]. Defects in the winding layer significantly affect the strength of the cylinder protection, posing a serious safety hazard. Therefore, rapid and accurate defect detection and inspection of the winding layer are key to ensuring the safety of CNG vehicles. Currently, the inspection of compositewound gas cylinders with steel liners is mainly based on ISO 19078:2006 "Inspection of the cylinder installation and requalification of high-pressure cylinders for the on-board storage of natural gas as a fuel for automotive vehicles," issued by the International Organization for Standardization in 2006. The methods for the classification and detection of defects described in this inspection standard have been cited in the product manuals and inspection guidelines of many mainstream gas cylinder manufacturers and inspection agencies in Europe and the United States [16-20]. However, there are issues in this standard. For example, the inspection method for composite-wound gas cylinders is relatively simple and mainly relies on visual inspection for defects. In addition, there is no effective nondestructive detection method for internal defects in the cylinder winding layers.

Therefore, developing a nondestructive testing method for CNG cylinders has become a focus of research. The current nondestructive testing methods for gas cylinders include ultrasonic testing, acoustic emission testing, and pulsed infrared thermal imaging testing [21]. The pulsed infrared thermal imaging method involves first increasing the cylinder temperature by external pulses and then detecting the surface temperature distribution of the winding layer using an infrared thermal imager [22]. Gas filling is another way to increase the cylinder temperature. Schmidlin and Dutton studied the fast filling process by filling a tubular vessel with a compressible gas and obtained the temperature field [23, 24]. Means studied the heat transfer process after gas injection and identified different heat transfer modes at various injection positions for various tank geometries [25]. Diggins investigated the effects of $\mathrm{CNG}$ cylinder material properties on fast filling operation [26]. These previous studies have shown that the filling process of gas cylinders is accompanied by an increase in temperature. This increase is caused by a combination of four factors during the filling process: (1) the injection of high-speed gas into the cylinder, with the kinetic energy converted into internal energy, (2) the work done by the compression of the gas in the cylinder, (3) the Joule-Thomson effect, and (4) heat exchanges between the inside and outside of the cylinder through the wall.

When a cylinder is filled with gas, the temperature increases in the cylinder, and the internal heat is conducted to the external environment through the steel layer and the winding layer. If defects exist in the winding layer of the cylinder, the heat conduction capacity at the defect is significantly lower than that in the surrounding area. The defect is equivalent to a source of thermal resistance, which hinders the conduction of heat and leads to an uneven temperature distribution on the surface of the winding layer. Researchers have obtained the surface temperature distribution of the cylinder during filling experiments by arranging thermocouples. Shen [27] analyzed the hydrogen charging and discharging process and measured the temperature changes by arranging temperature sensors throughout the inner and outer wall surfaces of a gas cylinder. Dicken [28] studied the filling process with a quantitative gas supply. Temperature sensors were installed on the inner wall of the cylinder to capture the heat exchange data. However, this method easily causes damage to the gas cylinder and has issues such as the difficulty of disassembly and inaccurate positioning.

In this study, infrared thermal imaging technology was employed to obtain the temperature distribution on the surface of a CNG cylinder. Defects in the cylinder winding layer hinder the conduction of heat, resulting in an uneven temperature distribution on the surface of the winding layer. The temperature difference can be seen as hot spots when using an infrared thermal imager to detect defects in the cylinder. Infrared thermal imaging is a technology that detects radiation information. Compared with temperature sensors, infrared thermal imaging has the advantages of a fast response time, a wide measurement range, being nondestructive, and not requiring contact, which meets the requirements for nondestructive testing in high-precision industries [29]. Infrared thermal imaging technology is widely used to inspect for internal defects and impact damage in aerospace composite components [30-37]. This technology has entered the engineering application stage and has been applied in an increasing number of fields [38-42].

In this paper, a three-dimensional model of a CNG composite-wound cylinder was established by using finite element simulation software. The change in the temperature of the cylinder wall during the filling process was monitored using infrared thermal imaging technology. The influence of winding layer defects on the temperature of the cylinder wall during the filling process was explored. The results of this study provide a basis and reference for the detection of defects in cylinder winding layers and a method for detecting winding layer defects based on thermal effects during gas filling.

\section{Detection principle}

There is a thermal effect during the gas filling process: as the temperature inside the gas cylinder continuously increases, a temperature difference is formed between the inside and the outside of the cylinder, and thus, heat is transferred to the external environment through the winding layer and the steel layer. Heat is transferred mainly through three mechanisms: heat conduction, heat convection, and heat radiation. Thermal convection occurs 
Fig. 1 Distribution of heat flow

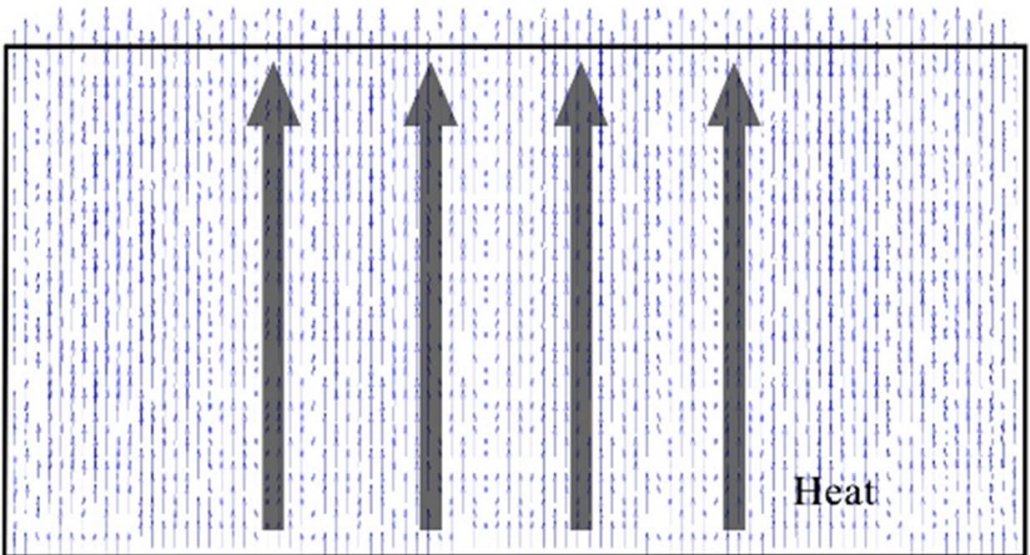

Thermal conductive layer

Table 1 Thermal conductivity

\begin{tabular}{llll}
\hline Material & Air & Steel layer & $\begin{array}{l}\text { Composite winding } \\
\text { layer }\end{array}$ \\
\hline $\begin{array}{l}\text { Thermal conductivity } \\
\text { W/(m K) }\end{array}$ & 0.024 & 44 & 0.2 \\
\hline
\end{tabular}

between the gas and the steel liner, heat conduction occurs between the steel liner and the winding layer, and heat convection and heat radiation occur between the winding layer and the external environment. This study only considered the heat conduction process; the heat radiation and heat convection processes were ignored to simplify the model. The overall structure of the gas cylinder is symmetrical. For a qualified gas cylinder, there are no protrusions or depressions on the inner or outer surfaces. Therefore, the temperature distribution on the outer wall of the cylinder is uniform during the filling process, and the direction of heat flow is perpendicular to the surface of the wall, as shown in Fig. 1. When there is a defect in the winding layer of the cylinder, the heat flow tends to propagate forward around the defect because the thermal conductivity of the air is lower than that of the winding layer (Table 1 [43]). The isotherms are perpendicular to the heat flow lines. Figure 2 shows that the isotherm has a significant depression; that is, the temperature distribution of the cylinder surface is uneven, indicating that the defect is equivalent to a source of thermal resistance that hinders heat transfer. The temperature differences can be captured

Fig. 2 Distribution of heat flow lines in the presence of defects

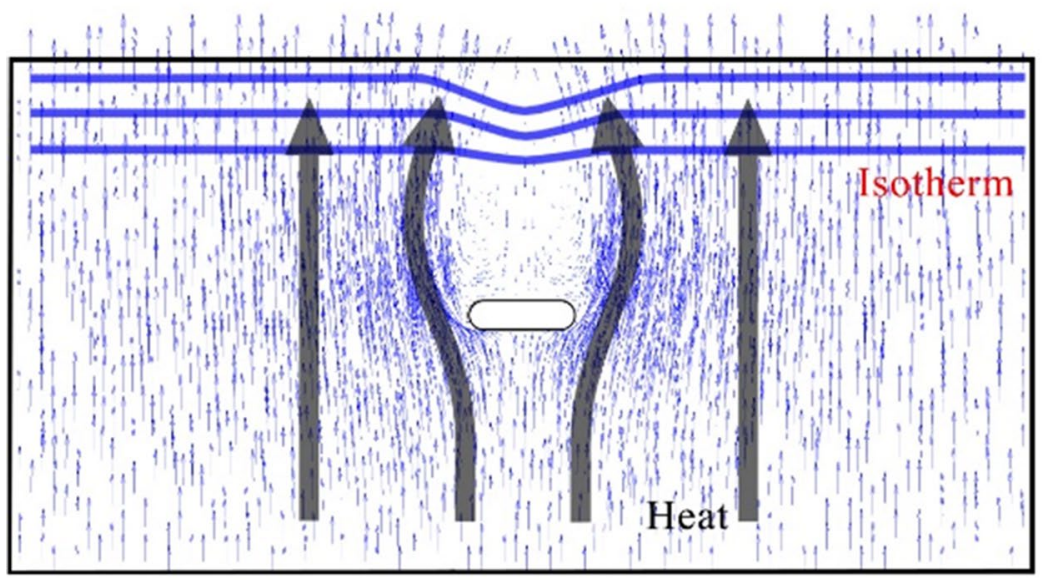


Table 2 Main parameters of the cylinder

\begin{tabular}{ll}
\hline Item & Parameter \\
\hline Cylinder type & $\begin{array}{c}\text { CNG-2 Hoop-wrapped com- } \\
\text { posite cylinders with steel } \\
\text { liner }\end{array}$ \\
CNG2-325-55-20B \\
Bottle specifications & D0338L865 \\
Outer diameter (mm) & 325 \\
Volume (L) & 55 \\
Working pressure (MPa) & 20 \\
Steel layer thickness (mm) & 5 \\
Winding layer thickness (mm) & 5 \\
Cylinder end structure & Hemispherical \\
Outlet thread & PZ27.8 \\
Fiber type & $158 B-A B-1100$ glass fiber \\
Resin type & EPIKOTEResin828 epoxy resin \\
\hline
\end{tabular}

Table 3 Thermophysical parameters of cylinder

\begin{tabular}{lrll}
\hline Parameter & Steel layer & $\begin{array}{l}\text { The composite } \\
\text { winding layer }\end{array}$ & Unit \\
\hline Thermal conductivity & 44 & 0.2 & $\mathrm{~W} /(\mathrm{mK})$ \\
Specific heat capacity & 460 & 1060 & $\mathrm{~J} /(\mathrm{mK})$ \\
Density & 7850 & 1500 & $\mathrm{~kg} / \mathrm{m}^{3}$ \\
\hline
\end{tabular}

by an infrared thermal imager as hot spots, which can be used to identify and measure the defects in the cylinder winding layers.

\section{CFD model construction and validation}

\subsection{CFD model construction}

The software Fluent is an application based on the finite element method. Fluent is widely used to simulate the physical processes of fluid flow and heat exchange and is applicable to complex processes such as high-speed flow fields and heat transfer [44]. This study used ANSYS-Fluent fluid dynamics simulation software to simulate the increase in the temperature of CNG composite-wound cylinders during the filling process.
In this paper, a CNG2-325-55-20B-type cylinder was selected as the object of the simulation. The main parameters of the cylinder are shown in Table 2 . The cylinder consists of two layers: an inner steel liner and an outer composite winding layer. The thermophysical parameters of the steel layer and the composite winding layer are shown in Table 3. The structure of the cylinder consists of four parts: the inner vessel, the steel layer, the winding layer, and the inlet. Meshing was carried out for each part. Mesh refinement was conducted at the inlet and each wall surface, and the total number of mesh units exceeded 2.53 million. The meshing results satisfied the mesh quality assessment rules. The model had a high mesh quality and clear structure and was thus representative of an actual gas cylinder.

Three defects, A, B, and C, were added to the threedimensional model of the gas cylinder. Defect $\mathrm{B}$ was located at the centerline of the cylinder, and defects $\mathrm{A}$ and $\mathrm{C}$ were symmetrically arranged at distances of $150 \mathrm{~mm}$ from the centerline of the cylinder. According to GB 24,162-2009 "Periodic inspection and evaluation of hoop wrapped fiber reinforced composite gas cylinders with metal liners of compressed natural gas for automotive vehicles," the damage in the winding layers can be classified into three types (Table 4). A defect with a depth of less than $0.25 \mathrm{~mm}$ is defined as primary damage, which refers to minor damage that occurs during normal use. Cylinders with primary damage can continue to be used. A defect at a depth greater than $0.25 \mathrm{~mm}$ but less than $1.25 \mathrm{~mm}$ is defined as secondary damage, which refers to damage that is more serious than primary damage but can be repaired. A defect at a depth greater than $1.25 \mathrm{~mm}$ is defined as tertiary damage, which refers to serious damage that occurs during use. Cylinders with tertiary damage can no longer be used. Based on this classification of winding layer damage, the depths of defects A, $\mathrm{B}$, and $\mathrm{C}$ were set to $0.25,0.75$, and $1.25 \mathrm{~mm}$, respectively. The CNG composite-wound cylinder model with a defective winding layer constructed in this study is shown in Fig. 3 .

\subsection{CFD model validation}

The main equipment of the gas filling experiment included an FLIRE50 infrared thermal imager, a CNG2-325-55-20Btype gas cylinder, and a gas supply controller. The pressure source used in this study was a pressure device consisting of a high-pressure tank and an air compressor. In the experiment, the surface temperature of the composite winding

Table 4 Types of winding layer damage and definitions

\begin{tabular}{llll}
\hline $\begin{array}{l}\text { Definition } \\
\text { Depth }\end{array}$ & $\begin{array}{l}\text { Primary damage (Acceptable damage) } \\
\text { Damage depth is less than } 0.25 \mathrm{~mm} \\
\text { No fiber exposure, cutting or separation }\end{array}$ & $\begin{array}{l}\text { Secondary damage (Repairable damage) } \\
\text { Damage depth is greater than } 0.25 \mathrm{~mm} \text { and less } \\
\text { than } 1.25 \mathrm{~mm} \text {, and can be repaired according } \\
\text { to the requirements of the manufacturer }\end{array}$ & $\begin{array}{l}\text { Damage depth is greater than } 1.25 \mathrm{~mm} \\
\end{array}$ \\
\hline
\end{tabular}


composite winding layer

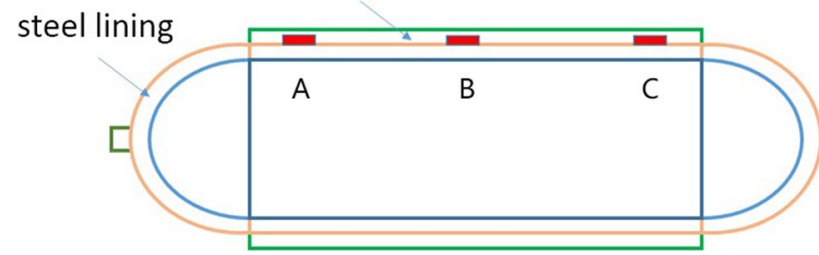

Fig. 3 CNG composite-wound cylinder model with a defective winding layer

layer of the cylinder was detected by the model FLIRE50 infrared thermal imager. The parameters and working conditions used in the filling experiment were consistent with those used in the simulation.

The temperature curves at defects $\mathrm{A}, \mathrm{B}$, and $\mathrm{C}$ obtained in the filling experiment were compared with the numerical simulation results at the corresponding positions
(Fig. 4). The simulated temperature curves were basically consistent with the experimental curves in all three cases. The temperature continuously increased with the filling time and reached the maximum at the end of the filling process. Differences were also observed between the experimental curves and the simulated curves. The reason for the difference is that during the actual filling process, the environmental temperature gradually increased, so the heat exchange between the wall surface and the external environment was reduced. However, the environmental parameters used in the simulation were fixed. A comparative analysis indicated that the parameters of the established cylinder model are appropriate. Thus, the gas filling process can be simulated well, reflecting the actual conditions, and the simulation results can provide reliable data support for subsequent research.

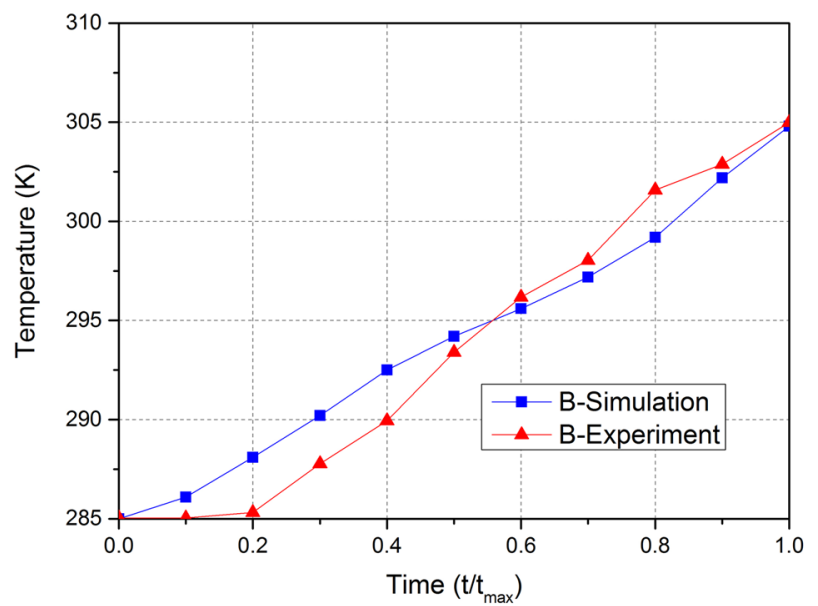

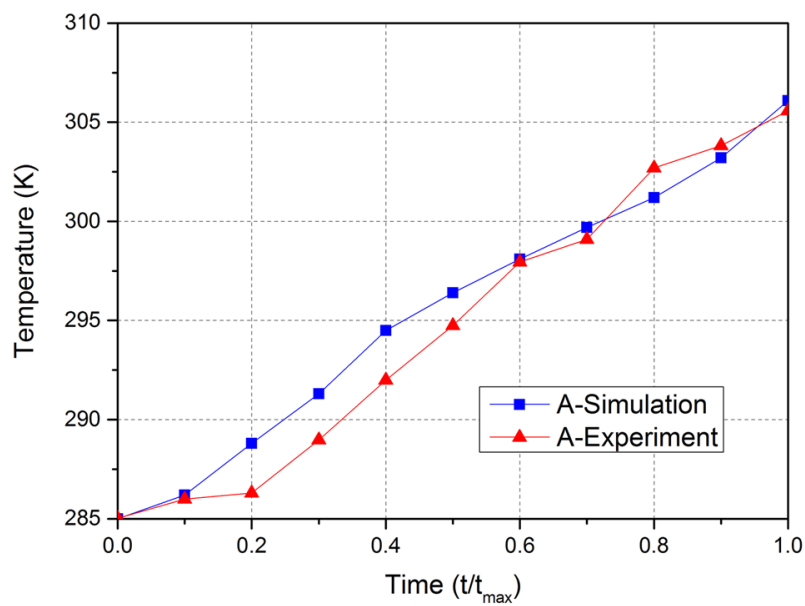

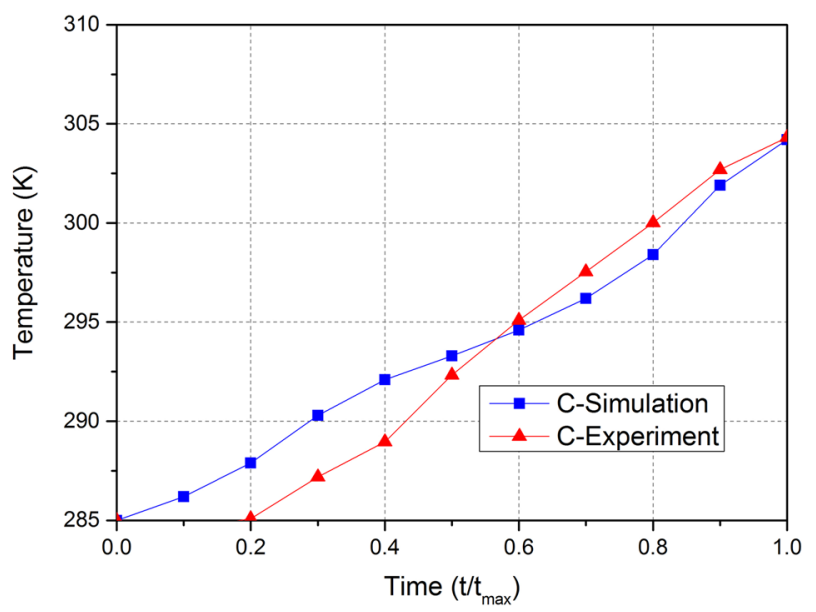

Fig. 4 Comparison of experimental temperature and simulated temperature at A, B, and C 


\section{Defect detection method for cylinder winding layer}

\subsection{Detection method}

To study the influence of the winding layer defect depth on the temperature and to explore the method for quantitatively evaluating the defect depth, we set the winding layer defect depth as a variable. The depths at defect $\mathrm{A}$ in the cylinder winding layer were set to $\mathrm{A} 1=1.25 \mathrm{~mm}, \mathrm{~A} 2=0.75 \mathrm{~mm}$, and $\mathrm{A} 3=0.25 \mathrm{~mm}$. Three simulations were carried out to obtain the temperature curves of A at different defect depths (Fig. 5). At the beginning and end of the filling process, the temperature curves almost overlapped, and the temperature differences between the three curves were almost zero. However, in the middle stage of the filling process, the temperature curves at different defect depths significantly differed. Therefore, a method for the quantitative detection of cylinder defects was established by quantifying the differences between cylinders with different winding layer defect depths during the middle stage of the filling process.

After the further processing of the simulation data, the gradient changes of the temperature curves under different defect depth conditions were obtained. The differences between the temperature curves obtained at different defect depths were amplified by normalization. Then, a parameter R closely related to the defect location and defect depth was proposed. The value of $\mathrm{R}$ reflects the deviation of the temperature at the defect from the temperature in the normal region.

$R=\frac{T_{d}-T_{s}}{T_{d}}$

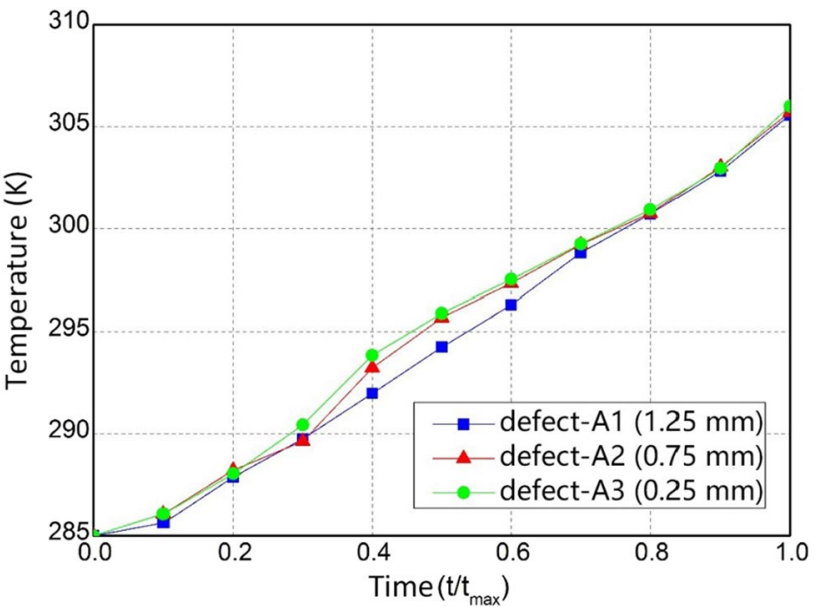

Fig. 5 Temperature curves at different defect depths where $T_{d}$ is the temperature at a nondefective point on the wall during filling and $\mathrm{T}_{\mathrm{s}}$ is the temperature at the defect on the wall during filling.

The simulation process was repeated on defects B and C using the same three defect depths as those for point $\mathrm{A}$. The $R$ values as a function of time at $\mathrm{A}, \mathrm{B}$, and $\mathrm{C}$ with different defect depths are shown in Fig. 6. In general, the $R$ value gradually increased during the initial stage of filling. After reaching the maximum, the $R$ value then gradually decreased until the end of filling. This effect occurs because a defect can be considered to be a source of thermal resistance in the heat transfer process, which can effectively hinder heat transfer. At the beginning of the filling process, the temperature inside the cylinder is low, and the difference between the temperatures of the inside and outside is limited. At this time, the hindrance in the heat transfer is not significant. As the temperature difference increases, the thermal resistance phenomenon becomes more pronounced, and the $R$ value gradually increases. After a certain period of time, the difference between the temperatures of the outside and inside of the cylinder gradually decreases, so the $R$ value gradually decreases.

Figure 6 shows that when the defect location is known, the defect depth and the maximum $R$ value are correlated. The deeper the defect is, the larger the maximum $R$ value is. The relationships between the defect depths at A, B, and $\mathrm{C}$ and the corresponding maximum $R$ value were established and are shown in Fig. 7. According to the criteria described in Sect. 2.1, the white region indicates that the defect is unacceptable and that the cylinder needs to be discarded. The blue and orange regions indicate that the defect is acceptable but needs to be repaired. The gray area indicates that the defect is acceptable, i.e., the cylinder meets the working condition requirements and can be used without repair.

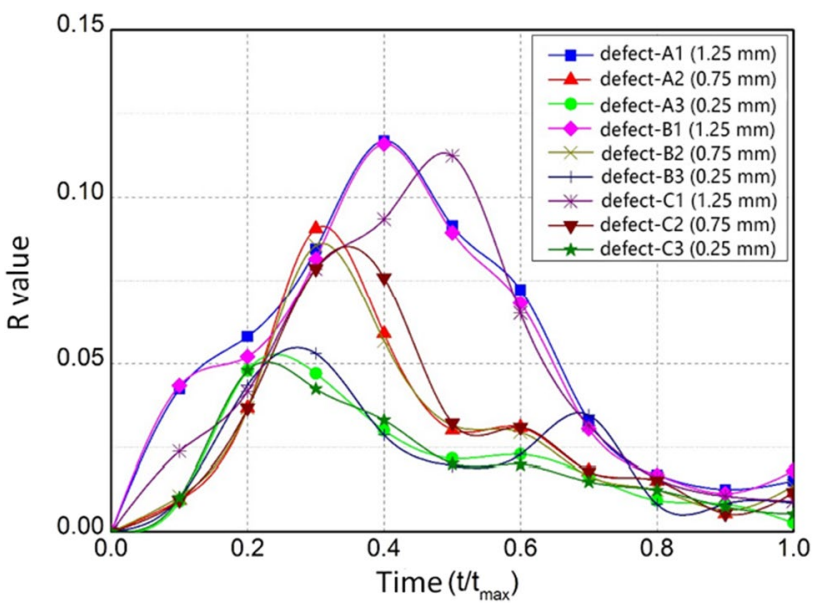

Fig. $6 R$ values for each defect at different depths 


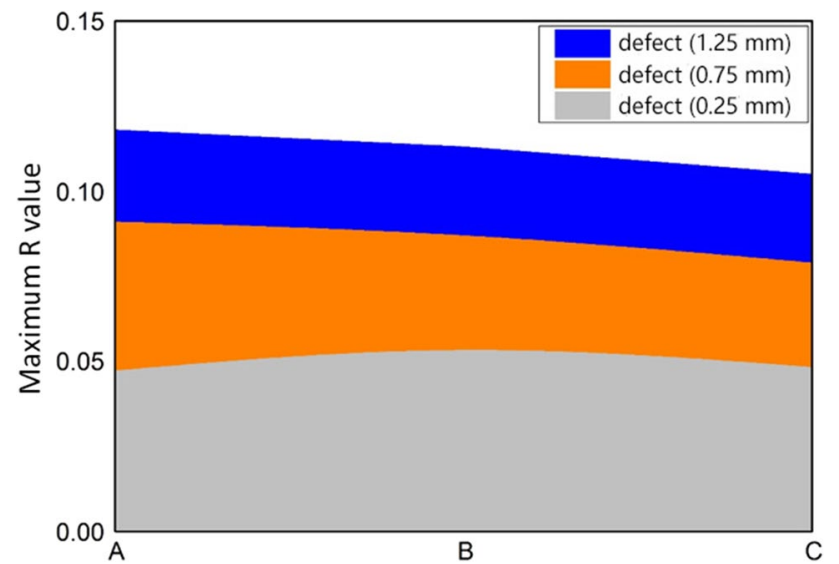

Fig. 7 Maximum $R$ value of each defect

When the defect location is known, a function can be fitted between the maximum $R$ value and the defect depth by using the correlation between these values and the boundary conditions. In engineering practice, a location with an abnormal temperature and the maximum $R$ value can be obtained by infrared thermal imaging technology. The depth of the defect in the winding layer can therefore be determined using the fitted relationship function.

\subsection{Application example of the detection method}

In this section, a composite-wound gas cylinder with defects in the winding layer was customized. A groove was cut at point $B$ to form a rectangular defect with a size of $10 \mathrm{~mm} \times 10 \mathrm{~mm} \times 1 \mathrm{~mm}$ in the winding layer, and another groove was cut at point $\mathrm{C}$ to form a rectangular defect with a size of $10 \mathrm{~mm} \times 10 \mathrm{~mm} \times 2 \mathrm{~mm}$. The gas filling experiment was performed on this cylinder. The $R$ values at defect $\mathrm{B}$ and defect $\mathrm{C}$ as a function of time were captured using infrared thermal imaging technology (Fig. 8). The maximum $R$ value was 0.138 at defect $\mathrm{B}$ and 0.0863 at defect $\mathrm{C}$. The two data points are marked in Fig. 9.

The maximum $R$ values of defect B at depths of $0.25 \mathrm{~mm}$, $0.75 \mathrm{~mm}$, and $1.25 \mathrm{~mm}$ can be determined from Fig. 6 . According to Eq. (1) ( $\mathrm{T}_{s}$ is the environmental temperature of $25{ }^{\circ} \mathrm{C}$ ), the maximum $R$ value of defect $\mathrm{B}$ was 0 at a $0 \mathrm{~mm}$ depth and 0.2 when the depth approached $5 \mathrm{~mm}$. The above data points and boundary points are listed in Table 5. Similarly, the data points and boundary points at defect $\mathrm{C}$ are listed in Table 6.

The data in Tables 5 and 6 were fitted well by a power function to obtain the maximum $R$ value-defect depth curves at defect $\mathrm{B}$ and defect $\mathrm{C}$ (Fig. 10). When the maximum $R$ value of defect B was 0.138 , the depth of defect B determined by the fitted curve was $2.11 \mathrm{~mm}$, while the actual depth was $2 \mathrm{~mm}$. Similarly, when the maximum $R$ value of

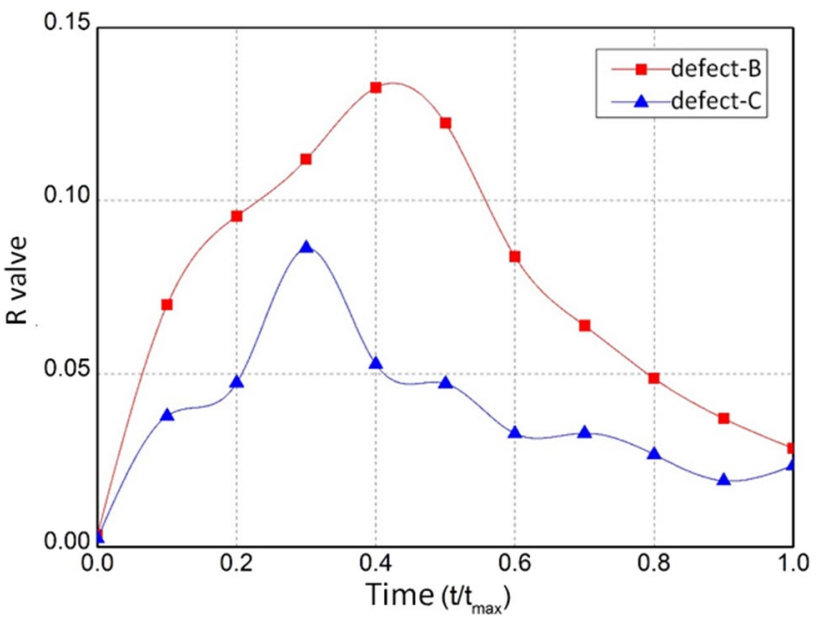

Fig. $8 R$ values at $\mathrm{B}$ and $\mathrm{C}$ as a function of time

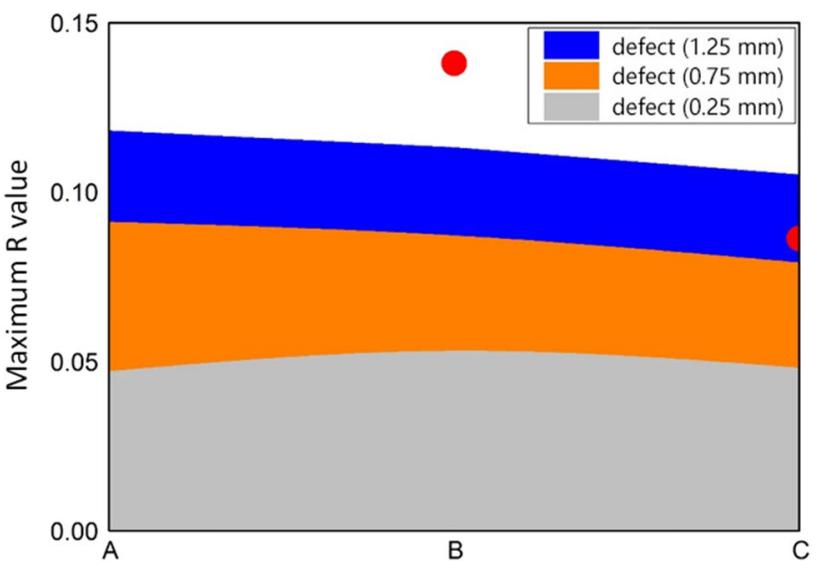

Fig. 9 Maximum $R$ values at defects B and C

Table 5 Data points and boundary points at defect B

\begin{tabular}{llllll}
\hline Depth of defect & $0 \mathrm{~mm}$ & $0.25 \mathrm{~mm}$ & $0.75 \mathrm{~mm}$ & $1.25 \mathrm{~mm}$ & $5 \mathrm{~mm}$ \\
$R$ value & 0 & 0.0473 & 0.056 & 0.675 & 0.20 \\
\hline
\end{tabular}

Table 6 Data points and boundary points at defect $\mathrm{C}$

\begin{tabular}{llllll}
\hline Depth of defect & $0 \mathrm{~mm}$ & $0.25 \mathrm{~mm}$ & $0.75 \mathrm{~mm}$ & $1.25 \mathrm{~mm}$ & $5 \mathrm{~mm}$ \\
$R$ value & 0 & 0.056 & 0.075 & 0.535 & 0.20 \\
\hline
\end{tabular}

defect $\mathrm{C}$ was 0.0863 , the depth of defect $\mathrm{C}$ determined by the fitted curve was $0.86 \mathrm{~mm}$, while the actual depth was $1 \mathrm{~mm}$. The method established in this paper can evaluate and classify defects at the level of the basic detection requirements. Thus, this method be used to quantitatively detect defects in a cylinder winding layer. 


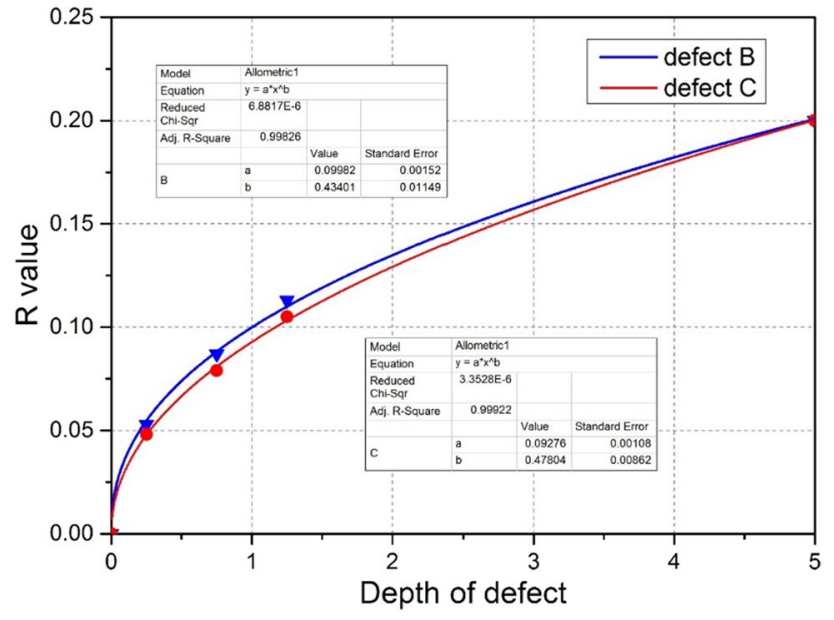

Fig. 10 Defect depth-maximum $R$ fitted curve

\section{Conclusions}

Defect detection technology for CNG composite-wound cylinders is essential to ensure the safety of NGVs. In this study, a gas cylinder model was constructed using simulation software, and the influence of winding layer defects on the temperature behavior during the gas filling process was studied. The results show the following:

(1) A defect in the winding layer of the cylinder acts as a source of thermal resistance that hinders heat transfer. The more serious the defect is, the greater the hindering effect is. The test data obtained by numerical simulation using this principle can quantify the severity of the defect to a certain extent.

(2) An evaluation model based on the $R$ parameter was proposed for changes in the temperature curves caused by defects. A quantitative correlation between the maximum $\mathrm{R}$ and the defect depth was established. Thus, this method provides a practical approach for the rapid detection and evaluation of defects in cylinder winding layers. Acknowledgements This work was supported by National Key R\&D
Program of China (Grant No. 2018YFC0809900).

Open Access This article is licensed under a Creative Commons Attribution 4.0 International License, which permits use, sharing, adaptation, distribution and reproduction in any medium or format, as long as you give appropriate credit to the original author(s) and the source, provide a link to the Creative Commons licence, and indicate if changes were made. The images or other third party material in this article are included in the article's Creative Commons licence, unless indicated otherwise in a credit line to the material. If material is not included in the article's Creative Commons licence and your intended use is not permitted by statutory regulation or exceeds the permitted use, you will need to obtain permission directly from the copyright holder. To view a copy of this licence, visit http://creativecommons.org/licenses/by/4.0/.

\section{References}

1. Guo, Z. H., \& Zhou, J. M. (2004). Characters of compressed natural gas automobile. Gas \& Heat., 24(2), 108-110. https:// doi.org/10.1117/12.832819

2. Wang, D. S. (2014). Experience and implication of Haze Governance in Europe and America Developed Countries. Electricity \& Energy., 35(2), 1-5.

3. Zhou, T., \& Ru, X. L. (2012). Study on causes and control measures of Haze Weather in Beijing. Journal of North China Electric Power University., 2, 12-16.

4. NGV Journal. (2018). Worldwide NGV Statistics. http://www. ngvjournal.com/worldwide-ngv-statistics/.

5. Hao, R. A., \& Li, X. D. (2007). Development of automotive fuel gas storage technology and adsorption storage materials. Materials Reports., 06, 75-79. https://doi.org/10.2514/1.26230

6. Zheng, J. Y., \& Li, J. Y. (2014). Technology trends of high-pressure vehicle fuel tanks and challenges for China. Pressure Vessel Technology., 31(02), 43-51.

7. Standards, Italian. (2002). Transportable Gas Cylinders-Fully Wrapped Composite Cylinders. Psychological interventions for non-ulcer dyspepsia (Full Cochrane Review).

8. Webster, C. (2001). The development of ISO 11439 for compressed natural gas vehicle cylinders. ISO Bulletin, 2, 15-19.

9. NZS. 5454-1989. Standard requirements for lightweight steel automotive compressed natural gas cylinders for use in New Zealand.

10. ANSI/CSA NGV2-1992. Basic Requirements for Compressed Natural Gas Vehicle (NGV) Fuel Containers.

11. CSA B51-1995. Boiler, Pressure Vessel, and Pressure Piping Code.

12. Xie, Y. M., \& Tan, Y. Q. (2002). The current situation and development of composite gas cylinders in the United States. Boiler and Pressure Vessel Safety Technology., 6, 15-17.

13. ISO 11439-2000. Gas cylinders-High pressure cylinders for the on-board storage of natural gas as a fuel for automotive vehicles.

14. ISO 11439-2013. Gas cylinders-High pressure cylinders for the on-board storage of natural gas as a fuel for automotive vehicles.

15. Xu, J. C., \& Yin, J. Z. (2012). Progress in filament-wound composite gas cylinders. Applied Science and Technology., 39(04), 64-71.

16. EIGA. European industrial gases association-AISBL. External prefill inspection for composite cylinders. [DB/OL]

17. Composite cylinders. Guidance for the use, inspection, care and periodic testing of SCI composite cylinders. [DB/OL]

18. Luxfer. (2009). Inc. Luxfer Carbon Composite Cylinders INSPECTION MANUAL. [DB/OL]

19. Lincolinc Composites. Fuel container inspection guidelines. [DB/ OL]

20. Siegfried Rivalta. Cylinder Inspection Manual. [DB/OL]

21. Liu, B., Peng, Z. J., Hu, B., Huo, Z., \& Li, X. D. (2018). Preliminary study on the timing and influencing factors of infrared thermal imaging detection of filament wound cylinders. Special Equipment Safety Technology., 04, 6-9.

22. Wang, Y., Zhang, W., Yang, Z. W., \& Meng, X. X. (2010). Infrared thermal wave testing on the lamination defect of glass fiber composite material. Nondestructive Testing., 32(11), 880-883. 
23. Dutton, J. C., \& Coverdill, R. E. (1997). Experiments to study the gaseous discharge and filling of vessels. International journal of engineering education., 13(2), 123-134.

24. Webster, C. (1999). Safety standards and inspection techniques for natural gas composite cylinders. Composite construction.

25. Means, J. D., \& Ulrich, R. D. (1975). Transient convective heat transfer during and after gas injection into containers. Journal of Heat Transfer., 97(2), 282-287. https://doi.org/10.1115/1.34503 56

26. Diggins, D.D. (1998). CNG fuel cylinder storage efficiency and economy in fast fill operations. SAE Technical Paper.

27. Shen, H. R., \& An, G. (2012). Temperature effects composite high pressure hydrogen storage cylinders in the rapid hydrogen charging and discharging process. Chemical Equipment Technology., 33(4), 18-21.

28. Dicken, C. J. B., \& Mérida, W. (2007). Measured effects of filling time and initial mass on the temperature distribution within a hydrogen cylinder during refuelling. Journal of Power Sources., 165(1), 324-336. https://doi.org/10.1016/j.jpowsour.2006.11.077

29. Chen, D. P., Mao, H. X., \& Xiao, Z. H. (2016). Infrared thermography NDT and its development. Computer Measurement \& Control., 24(04), 1-6.

30. Schroeder, J. A., Ahmed, T., \& Chaudhry, B. (2002). Non-destructive testing of structural composites and adhesively bonded composite joints: Pulsed thermography. Composites Part A: Applied Science and Manufacturing., 33(11), 1511-1517. https://doi.org/ 10.1016/S1359-835X(02)00139-2

31. Almond, D. P., \& Peng, W. (2001). Thermal imaging of composites. Journal of Microscopy., 201(2), 163-170. https://doi.org/10. 1046/j.1365-2818.2001.00762.x

32. Ball, R. J., \& Almond, D. P. (1998). The Detection and measurement of impact damage in thick carbon fiber reinforced laminates by transient thermography. NDT\&E International., 31(3), 165-175. https://doi.org/10.1016/s0963-8695(97)00052-2

33. Angelidis, N., \& Irving, P. E. (2007). Detection of impact damage in CFRP laminates by means of electrical potential techniques. Composites Science and Technology., 67(3), 594-604. https://doi. org/10.1016/j.compscitech.2006.07.033

34. Chambers, A. R., Mowlem, M. C., \& Dokos, L. (2007). Evaluating impact damage in CFRP using fiber optic sensors. Composites Science and Technology., 67(6), 1235-1242. https://doi.org/10. 1016/j.compscitech.2006.05.023

35. Wu, D., Salerno, A., \& Busse, G. (1998). Lockin-thermography for non-de-structive evaluation of aerospace structures. Copenhagen: NDT. 3(9), 26-29.

36. Dillenz, A., Busse, G., \& Wu, D. (1999). Ultrasound Lock-in thermography: feasibilities and limitation. Munich: SPIE. 3827, pp 10-15. https://doi.org/10.1117/12.361008.

37. Vallerand, S., \& Maldague, X. (2000). Defect Characterization in pulsed thermography: A statistical method compared with Kohonen and perceptron neural networks. NDT\&E International., 33(5), 307-315. https://doi.org/10.1016/s0963-8695(99)00056-0

38. Jones, H. G., Serraj, R., \& Loveys, B. R. (2009). Thermal infrared imaging of crop canopies for the remote diagnosis and quantification of plant responses to water stress in the field. Functional Plant Biology., 36(11), 978. https://doi.org/10.1071/FP09123

39. Leifer, I., \& Lehr, W. J. (2012). State of the art satellite and airborne marine oil spill remote sensing: Application to the BP Deepwater Horizon oil spill. Remote Sensing of Environment., 124, 26. https://doi.org/10.1016/j.rse.2012.03.024

40. Lee, W. S., et al. (2010). Sensing technologies for precision specialty crop production. Computers \& Electronics in Agriculture., 74(1), 2-33. https://doi.org/10.1016/j.compag.2010.08.005

41. Torresan, C., \& Wallace, L. (2016). Forestry applications of UAVs in Europe: A review. International Journal of Remote Sensing. https://doi.org/10.1080/01431161.2016.1252477
42. Zheng, E. H., \& Cao, W. H. (2013). Analysis of Temperature field on Near Surface Defect in Infrared Nondestructive Testing. Computer Simulation., 30(4), 416-420.

43. Ma, Q. F., Fang, R. S., \& Xiang, L. C. (1986). Practical Thermophysical Properties Handbook. China Agricultural Machinery Press.

44. Wang, F. J. (2004). Computational fluid dynamics analysis. Tsinghua University Press.

Publisher's Note Springer Nature remains neutral with regard to jurisdictional claims in published maps and institutional affiliations.

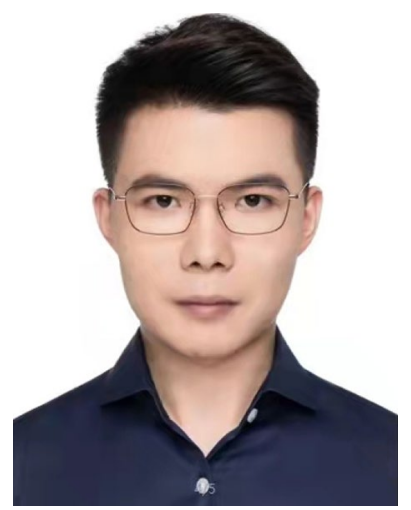

Hui Lv is a researcher at the Institute of Public Safety Research, Department of Engineering Physics, Tsinghua University. He received a master degree in Safety Engineering from Tsinghua University in 2021. His main areas of interest are mechanical and thermal analyses for risk assessment.

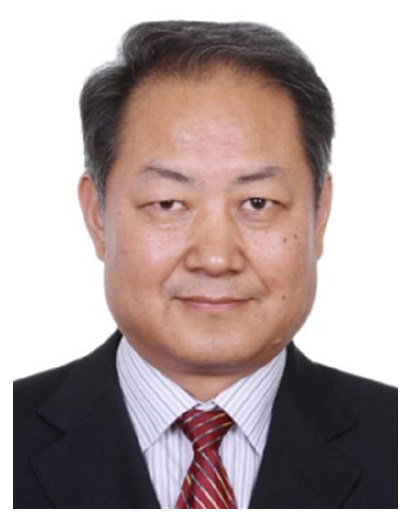

Gongtian Shen is a research fellow at the China Special Equipment Inspection and Research Institute and received a Ph.D degree in mechanical engineering from Tsinghua University in 1998. His main areas of interest are $\mathrm{R} \& \mathrm{D}$ of new nondestructive testing technology such as acoustic emission testing, electromagnetic testing and infrared thermography testing.

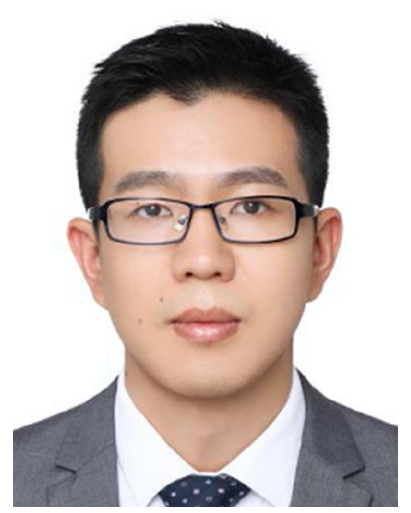

Yue $\mathrm{Yu}$ is a researcher at the China Special Equipment Inspection and Research Institute and received a master degree in aerospace science and technology from Tsinghua University in 2009. His main areas of interest are $R \& D$ of new nondestructive testing technology such as Infrared thermography testing, terahertz testing. 


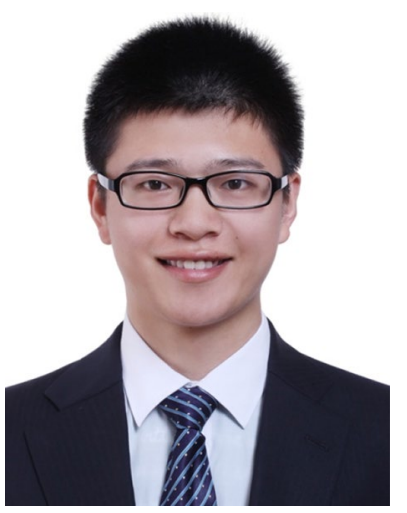

Lixiong Zhu received a MS degree in Safety Engineering from Tsinghua University in 2016. His research interests include thermal analyses in energy and safety areas.

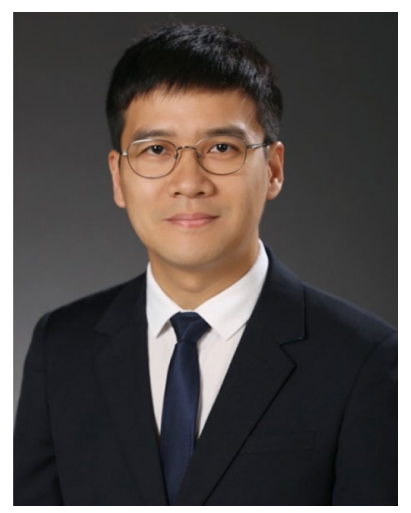

Rui Zhou is an associate research fellow at the Institute of Public Safety Research, Department of Engineering Physics, Tsinghua University. He received a Ph.D degree in Engineering Mechanics from Tsinghua University in 2009. His main areas of interest are mechanical and thermal analyses for public safety and risk assessment. 